\title{
The risk of cumulative radiation exposure in chest imaging and the advantage of bedside ultrasound
}

\author{
Luna Gargani* and Eugenio Picano
}

\begin{abstract}
The increasing use and complexity of imaging techniques have not been matched by increasing awareness and knowledge by prescribers and practitioners. Imaging examinations that expose to ionizing radiation provide immense benefits when appropriate, yet they may result in an increased incidence of radiation-induced cancer in the long-term. The radiation issue is relevant not only for the individual patient but also for the community because small individual risks multiplied by millions of examinations become a significant population risk. As recently highlighted by recent European and American Guidelines, the long-term risk associated with radiation exposure should be considered in the risk-benefit assessment behind appropriate prescription of diagnostic testing.
\end{abstract}

Keywords: Radiation exposure; Chest imaging; Point of care; Lung ultrasound

\section{Introduction}

The fast and strong development of medical imaging represents an exceptional success in the history of medicine. Imaging tests are now the mainstay of our diagnostic approach in many diseases: they allow detection of anatomical and physiological abnormalities often unmasking clinically silent conditions, they are crucial to guide treatment and they can be life-saving. Nevertheless, the widespread use of imaging techniques poses some relevant concerns about the unsustainable society costs and the non-negligible health risks of an inappropriate use [1-3].

\section{Review}

Why is radiation an issue?

Medical radiation from X-rays and nuclear medicine is the largest man-made source of radiation exposure in Western countries [4]. Ionizing radiation including X-rays and $\gamma$ rays are well-known proven carcinogens, according to the classification of the World Health Organization's International Agency for Research on Cancer [5]. Radiation's deleterious effects are typically classified as stochastic effects that are due to radiation-induced mutations and deterministic effects (i.e. tissue reactions) due to radiation-induced cell death. Deterministic effects only occur above a threshold level of radiation, which is

\footnotetext{
* Correspondence: gargani@ifc.cnr.it

Institute of clinical Physiology, National Research Council, via Moruzzi 1, 56124 Pisa, Italy
}

\section{Springer}

(c) 2015 Gargani and Picano; licensee Springer. This is an Open Access article distributed under the terms of the Creative Commons Attribution License (http://creativecommons.org/licenses/by/4.0), which permits unrestricted use, distribution, and reproduction in any medium, provided the original work is properly credited. generally higher than levels occurring from a single non-invasive imaging procedure. The risk of developing cancer deriving from radiation exposure is mainly stochastic, which means that it may occur without a specific threshold level, although the magnitude of this risk remains unclear, particularly at very low doses. The risk is also cumulative.

According to the risk estimates released in the Seventh Report of the Committee to Assess Health Risks from Exposure to Low Levels of Ionizing Radiation, the attributable risk of cancer is $1 / 750$ for $15 \mathrm{mSv}$ exposure [4]. Radiation-induced cancers typically do not occur until one or two decades or even longer after exposure. Thus, any increase in cancer occurrence due to medical imaging may not be expected to be evident for many years after exposures. Radiological dose estimate can be expressed as multiples of a single postero-anterior chest $\mathrm{X}$-ray (equal to 0.02 milliSievert, $\mathrm{mSv}$ ), as originally suggested by the UK College of Radiologists and endorsed in the European Commission referral guidelines on medical imaging [6] and - more recently - by the European Society of Cardiology position paper on medical radiation [2] (Table 1).

\section{Women and children first}

For each dose, the risk varies greatly depending on the age (lower in the elderly) and gender (about 38\% higher in women than in men at all ages of life) [2]. Children 
Table 1 Standard average estimated radiation doses of common non-invasive chest imaging in adults (modified from refs. [2] and [21])

\begin{tabular}{lll}
\hline Diagnostic procedures & Effective dose (mSv) & Equivalent CXRs number \\
\hline Radiology & & 1 \\
Chest radiography (single postero-anterior film) & 0.02 & 300 to 400 \\
Chest CT & 6 to 8 & $750(150$ to 1,600$)$ \\
64-slice coronary CT & $15(3$ to 32) & 150 \\
Calcium score & $3(1-12)$ & 470 \\
Nuclear medicine & & 2,035 \\
${ }^{99 m}$ Tc-Sestamibi (1100 MBq, 1 day) stress-rest & 9.4 & 120 \\
${ }^{201}$ Thallium stress/rest reinj. (185 MBq, double injection) & 40.7 & 400 \\
PET N-13 ammonia stress-rest (1100 MBq) & 2.4 & 20 \\
PET F-18 FDG rest (400 MBq, viability) & 8 & 100 \\
${ }^{133}$ Xenon (400 MBq, lung ventilation) & 0.4 & 2 \\
${ }^{99 m}$ Tc-MAA (185 MBq, lung perfusion) & 2 & \\
\hline
\end{tabular}

are at substantially higher risk than adults because they have more rapidly dividing cells and a greater life expectancy. Thus, an infant or child patient has a longer lifetime risk for developing radiation-induced cancers than adult patients. A recent study has reported that the average child in the US receives seven medical imaging tests involving radiation by the time he or she reaches the age of 18 [7].

The issue of radiological responsibility in children was recently addressed in the US with the Image Gently, Step Lightly Campaign, focused on the risks of unnecessary and excessive medical radiation exposure from interventional radiology administered to paediatric patients [8]. The European directive 2013/59/euratom (art. 61) underlines that special attention shall be given to quality assurance programmes and the assessment of dose in medical exposure of children [9].

\section{How much are we aware?}

Many data clearly show that both patients and doctors including radiologists, cardiologists, paediatricians, and nuclear cardiologists - have until recently been largely unaware of the long-term risk of the imaging studies they commonly use $[10,11]$. Patients obviously have the right to know, according to medical deontological code and the law [9], but our informed consent forms are usually reticent or impossible to understand in their parts addressing radiological risk [12,13]. The White Paper on Radiation Dose in Medicine underlines that 'It is incumbent on radiologists to assume the responsibility for their patient's safety with regard to radiation exposure. They should also educate their patients on these issues so they may make informed decisions about their health care' [14]. The White Paper states also that 'Although some referring physicians are very knowledgeable regarding safety issues and incorporate such information into their imaging decisions, others have had little or no training in radiation exposure and do not routinely consider this factor when ordering imaging examinations' [14]. Even though the law already imposes specific behaviours designed to protect against the dangers arising from exposure to ionizing radiation [9], some wrong practices are still very common (Table 2).

\section{Chest imaging}

The number of CT scans of all types performed in the USA has quadrupled since 1993, and the same increasing trend has also been observed in Europe [15]. The increase in imaging utilization has led to a nearly sixfold increase in the per capita dose of radiation from medical imaging occurred in the USA between 1982 and 2007. Chest imaging exposing to ionizing radiation includes chest X-ray and chest CT but also coronary CT angiography, nuclear cardiology, invasive coronary angiography and angioplasty, which account for a significant percentage of all diagnostic examinations. The chest is the most frequently evaluated region of the body in children [15]. CT scans account for $8 \%$ of exams in the paediatric population, and data show that they are often performed without adjusting exposure parameters to weight, resulting in up to $50 \%$ of the dose being unnecessary [15]. Moreover, radiological chest imaging should be especially well justified and carefully optimized in women because from the radiobiological viewpoint the female breast is a highly radiosensitive organ [4].

The radioprotection issue is intrinsically linked also to the appropriateness issue. Some recent studies have shown significant percentages of partially or totally inappropriate radiological examinations, even in top-level academic medical centres [16,17]. Exams that are not appropriate should not be performed, but exams that are not appropriate and yield even a very low biological risk 
Table 2 Radiation in paediatric imaging: current and future approaches (modified from ref. [23])

\begin{tabular}{lll}
\hline & Current approach & What we need \\
\hline Patient & More (exams) is better & Less (dose) is better \\
Culture & Absent & Present \\
Radiation history & Absent & Present and informative \\
Radiological informed consent & Missing & Mandatory \\
Received dose in report & Ignored & Considered \\
Organ dose & & Preventing cancer \\
Doctor/scientist & Matter of investigation for physicists \\
Optimizing dose & Focused on short-term costs & Focused on long-term risks \\
Technology upgrading & Population-based & Personalized \\
Radiological risk estimation & Offline, months later & Online, real time \\
Dose reading & &
\end{tabular}

to the patient should be avoided. The inappropriateness of imaging techniques, especially when exposing to ionizing radiation, is becoming economically and socially unsustainable.

Bedside point-of-care ultrasonography is emerging as a crucial bedside tool that allows timely decision-making, especially in critically ill patients. Besides conventional ultrasonography, point-of-care echo is a new diagnostic approach to help the attending physicians answer specific questions that are clinically focused and need rapid response.

This new way of using the probe as an extension of the examining hand and ear is gaining consensus especially in intensive care units and emergency departments but also for the management of more stable patients. CT definitively remains the gold standard imaging tool for most conditions, but the implications of transferring a critically ill patient out of ICU have stimulated the scientific community and physicians to approve this innovative and revolutionary approach to ultrasound [18]. Accordingly, the recent introduction of lung ultrasound in the clinical practice has been paradigmatic, and from a counterintuitive use of sonography, the technique is now being used more and more frequently, both in acute and chronic settings [19]. When we choose lung ultrasound as a firstline exam instead of more complex and costly chest CT, it is not for radioprotection issues, but for the advantages of a bedside, rapidly available, highly versatile technique. However, it may be also useful to reduce our patients' exposure and, in specific populations, it may be the test of choice for the initial screening of interstitial lung disease [20]. In patients with chronic conditions, an extensive use of CT for a tight follow-up is indeed limited by the non-negligible cumulative radiation exposure of this examination.

It is crucial that the new generations of physicians and health care providers are no longer unaware of the basics of radioprotection. The White Paper itself suggests a profound remodelling of radioprotection teaching. It is advised that 'education of future referring physicians on radiation exposure to patient during diagnostic imaging should begin during medical school. The goal is to develop the awareness of radiation exposure in students during training. Any clinician should be steered toward an imaging regimen that minimizes radiation.' [14] The two very recent documents of the American Heart Association and European Society of cardiology both witness the attention paid by non-radiological societies to the radiation issue and emphasize concordantly that a responsible use of medical radiation should rest on three pillars: Justification (only appropriate tests should be done), Optimization (only the right dose should be used) and Education (both doctors and patients should be aware of what they do, in terms of radiological doses and risks) $[2,3]$. In chest imaging, this means very pragmatically to implement, whenever possible, the expertise to shift the diagnosis from ionizing imaging testing to non-ionizing techniques, for instance with lung ultrasound integrating - and in selected case replacing - chest X-ray and chest CT whenever possible [21].

\section{Conclusions}

Underlining the importance of radiological awareness does not translate in an underestimation of the crucial, irreplaceable role of some imaging techniques and examinations that can be life-saving and have dramatically changed the management of some serious illness. The risks of a test should always be weighed against the risks if a disease remains undetected, detected at a later stage, incorrectly prognosticated or suboptimally treated [22]. It is however not recommended to perform tests involving ionizing radiation when the desired information can be obtained with a non-ionizing test with comparable accuracy [2]. We cannot only rely on the benefit of the medical procedures we propose to our patients, but we have to include long-term cancer risks in the risk-benefit 
assessment of diagnostic or therapeutic testing. The cultural benefit of remodelling our awareness about medical radiation exposure will be immense to enhance the protection of patients and physicians themselves and to ultimately provide better patient care. As stated in the recent European Society of Cardiology Position paper on use of medical radiation in cardiovascular imaging, a smart physician 'cannot be afraid of the essential and often life-saving use of medical radiation, but must be very afraid of radiation unawareness' [2].

\section{Competing interests}

The authors declare that they have no competing interests.

\section{Authors' contributions}

Both $L G$ and EP contributed to the conception and design of the paper. LG drafted the manuscript that was critically revised by EP. Both authors gave final approval of the version to be published.

\section{Acknowledgements}

The authors would like to thank Ms. Letizia Morelli for her technical assistance during the preparation of the manuscript.

Received: 5 January 2015 Accepted: 4 February 2015

Published online: 28 March 2015

\section{References}

1. Picano E (2004) Sustainability of medical imaging. BMJ 328:578-80, Education and Debate

2. Picano E, Vañó E, Rehani MM, Cuocolo A, Mont L, Bodi V, Bar O, Maccia C, Pierard L, Sicari R, Plein S, Mahrholdt H, Lancellotti P, Knuuti J, Heidbuchel H, Di Mario C, Badano LP (2014) The appropriate and justified use of medical radiation in cardiovascular imaging: a position document of the ESC Associations of Cardiovascular Imaging, Percutaneous Cardiovascular Interventions and Electrophysiology. Eur Heart J 35(10):665-72

3. Fazel R, Gerber TC, Balter S, Brenner DJ, Carr JJ, Cerqueira MD, Chen J, Einstein AJ, Krumholz HM, Mahesh M, McCollough CH, Min JK, Morin RL, Nallamothu BK, Nasir K, Redberg RF, Shaw $\sqcup$ (2014) American Heart Association Council on Quality of Care and Outcomes Research, Council on Clinical Cardiology, and Council on Cardiovascular Radiology and Intervention. Approaches to enhancing radiation safety in cardiovascular imaging: a scientific statement from the American Heart Association. Circulation 130(19):173-48

4. Committee to Assess Health Risks from Exposure to Low Levels of lonizing Radiation. Health risks from exposure to low levels of ionizing radiation: BEIR VII Phase 2. Washington, DC: The National Academies Press; 2006. [http://www.nap.edu/openbook.php?isbn=030909156X].

5. World Health Organization, International Agency for Research on Cancer: Overall evaluations of carcinogenicity to humans, list of all agents evaluated to date. [http//monographs.iarc.fr/ENG/Classification/ClassificationsAlphaOrder.pdf].

6. Commission E (2001) Radiation protection 118: referral guidelines for imaging. Office for Official Publications of the European. Communities, Luxembourg

7. Dorfman AL, Fazel R, Einstein AJ, Applegate KE, Krumholz HM, Wang Y, Christodoulou E, Chen J, Sanchez R, Nallamothu BK (2011) Use of medical imaging procedures with ionizing radiation in children: a population-based study. Arch Pediatr Adolesc Med 165:458-64

8. Sidhu M, Coley BD, Goske MJ, Connolly B, Racadio J, Yoshizumi TT, Utley T, Strauss KJ (2011) Image Gently Step Lightly: increasing radiation dose awareness in pediatric interventional radiology. Pediatr Radiol 39:1135-8

9. COUNCIL DIRECTIVE (2013) 2013/59/EURATOM of 5 December 2013 laying down basic safety standards for protection against the dangers arising from exposure to ionising radiation, and repealing Directives 89/618/ Euratom, 90/641/Euratom, 96/29/Euratom, 97/43/Euratom and 2003/122/Euratom

10. Lee Cl, Haims AH, Monico EP, Brink JA, Forman HP (2004) Diagnostic CT scans: assessment of patient, physician, and radiologist awareness of radiation dose and possible risks. Radiology 231(2):393-8
11. Einstein AJ, Tilkemeier P, Fazel R, Rakotoarivelo H, Shaw LJ, American Society of Nuclear Cardiology (2013) Radiation safety in nuclear cardiology-current knowledge and practice: results from the 2011 American Society of Nuclear Cardiology member survey. JAMA Intern Med 173(11):1021-3

12. Picano E (2004) Informed consent and communication of risk from radiological and nuclear medicine examinations: how to escape from a communication inferno. BMJ 329(7470):849-51

13. Terranova G, Ferro M, Carpeggiani C, Recchia V, Braga L, Semelka RC, Picano E (2012) Low quality and lack of clarity of current informed consent forms in cardiology: how to improve them. JACC Cardiovasc Imaging 5(6):649-55

14. Amis ES Jr, Butler PF, Applegate KE, Birnbaum SB, Brateman LF, Hevezi JM, Mettler FA, Morin RL, Pentecost MJ, Smith GG, Strauss KJ, Zeman RK (2007) American College of Radiology white paper on radiation dose in medicine. J Am Coll Radiol 4:272-84

15. Frush DP (2011) Radiation, thoracic imaging, and children: radiation safety. Radiol Clin North Am 49(5):1053-69

16. Gibbons RJ, Miller TD, Hodge D, Urban L, Araoz PA, Pellikka P, McCully RB (2008) Application of appropriateness criteria to stress single-photon emission computed tomography sestamibi studies and stress echocardiograms in an academic medical center. J Am Coll Cardiol 51:1283-9

17. Carpeggiani C, Marraccini P, Morales MA, Prediletto R, Landi P, Picano E (2013) Inappropriateness of cardiovascular radiological imaging testing; a tertiary care referral center study. PLoS One 8(11):e81161

18. Via G, Storti E, Gulati G, Neri L, Mojoli F, Braschi A (2012) Lung ultrasound in the ICU: from diagnostic instrument to respiratory monitoring tool. Minerva Anestesiol 78(11):1282-96

19. Volpicelli G, Elbarbary M, Blaivas M, Lichtenstein DA, Mathis G, Kirkpatrick AW, Melniker L, Gargani L, Noble VE, Via G, Dean A, Tsung JW, Soldati G, Copetti R, Bouhemad B, Reissig A, Agricola E, Rouby JJ, Arbelot C, Liteplo A, Sargsyan A, Silva F, Hoppmann R, Breitkreutz R, Seibel A, Neri L, Storti E, Petrovic T, International Liaison Committee on Lung Ultrasound (ILC-LUS) for International Consensus Conference on Lung Ultrasound (ICC-LUS) (2012) International evidence-based recommendations for point-of-care lung ultrasound. Intensive Care Med 38(4):577-91

20. Barskova T, Gargani L, Guiducci S, Randone SB, Bruni C, Carnesecchi G, Conforti ML, Porta F, Pignone A, Caramella D, Picano E, Cerinic MM (2013) Lung ultrasound for the screening of interstitial lung disease in very early systemic sclerosis. Ann Rheum Dis 72(3):390-5

21. Picano E, Semelka R, Ravenel J, Matucci-Cerinic M (2014) Rheumatological diseases and cancer: the hidden variable of radiation exposure. Ann Rheum Dis 73(12):2065-8

22. Einstein AJ, Knuuti J (2012) Cardiac imaging: does radiation matter? Eur Heart J 33(5):573-8

23. Andreassi MG, Picano E (2014) Reduction of radiation to children: our responsibility to change. Circulation 130(2):135-7

\section{Submit your manuscript to a SpringerOpen ${ }^{\mathcal{D}}$ journal and benefit from:}

- Convenient online submission

- Rigorous peer review

- Immediate publication on acceptance

- Open access: articles freely available online

- High visibility within the field

- Retaining the copyright to your article

Submit your next manuscript at $>$ springeropen.com 